\title{
Automated characterization of varnishes photo-degradation using portable T-controlled Raman spectroscopy
}

\author{
I. Osticioli *, D. Ciofini, A.A. Mencaglia, S. Siano \\ Institute of Applied Physics “Nello Carrara” (IFAC-CNR), Florence, Italy
}

\section{A R T I C L E I N F O}

\section{Article history:}

Received 6 November 2015

Received in revised form 8 January 2016

Accepted 16 March 2016

Available online 17 March 2016

\section{Keywords:}

Molecular spectroscopy

Ageing

Resins

Terpenoid

Dynamics

Portable

\begin{abstract}
A B S T R A C T
In this work, a portable-Raman device (excitation wavelength $1064 \mathrm{~nm}$ ) was employed for the first time for continuously monitoring the complex molecular dynamics of terpenoid resins (dammar, mastic, colophony, sandarac and shellac), which occur during their ageing under artificial light exposure. The instrumentation was equipped with a pyroelectric sensor allowing for temperature control of the sample's irradiated surface while the acquisition of spectra occurs by setting fixed maximum temperature and total radiant exposure. Resins were dropped into special pits over a dedicated rotating wheel moved by a USB motor. The rotation allowed samples sliding between the positions designated for the acquisition of the Raman spectra and that for artificial ageing. Samples were exposed to artificial light for 45 -days and almost 400 spectra for each resin sample were collected. The exposure to artificial light led to significant changes allowing the characterization of the alteration process. The automated acquisition of a large number of spectra overtime during light-exposure has given the possibility to distinguish fast dynamics, mainly associated to solvent evaporation, from those slower due to resins photo-degradation processes.
\end{abstract}

(c) 2016 Elsevier B.V. All rights reserved.

\section{Introduction}

All natural varnishes undergo ageing and degradation course overtime, changing their chemical and physical properties. The characterization of the alteration is a crucial issue concerning cultural heritage artefacts in order to have a reliable and trustful diagnosis of their state of conservation [1].

The ageing process can definitely affect the stability of the artefact because of the destruction of the material itself as well as the loss of its flexibility and cohesion properties. Similarly, change in color and growth of cracks can alter the legibility as well. Depending on external factors, degradation can be of thermal, hydrothermal, chemical, photochemical or mechanical origin.

In this scenario, the understanding of molecular changes involved in degradation becomes crucial for a more correct and durable conservation intervention. Among the materials used in the field of art, organic polymers are indeed those subject to more complex ageing and degradation processes [2]: auto-oxidative processes through chain radical reactions, photo-dissociative processes along with the generation of cross-linking, condensations, chain shortening and defunctionalization as well as bond breaking and disintegration are example of what may happen during the alteration processes.

\footnotetext{
* Corresponding author at: Institute of applied physics "Nello Carrara" (IFAC - CNR), via Madonna del Piano 10, 50019, Sesto Fiorentino (FI), Italy.

E-mail address: i.osticioli@ifac.cnr.it (I. Osticioli).
}

The identification of altered compounds is usually carried out by means of mass spectrometry, which requires sampling and sample pre-treatment [3-5]. FTIR spectroscopy is used for the identification and discrimination between organic and inorganic species [6] as well as for the assessment of the photodegradation kinetics of solvent and oil-based varnishes [7].

These techniques are nowadays employed not only to assess molecular changes due to the degradation of the polymer itself but also to understand how its interaction with other materials (i.e. heavy-metals ions, pigments and other binders) may affect the time of ageing and determine the formation of specific compounds [8-11].

In this scenario, Raman and non-contact IR spectroscopy can allow to assess chain reactions and identify the formation of specific degradation products without any sampling and sample preparation $[12,13]$. However, in the present application IR spectroscopy is more suited for describing molecular processes involving mainly $\mathrm{C}=0$ molecular vibrations, whereas Raman spectroscopy can provide a wider and more detailed picture of the alteration dynamics thank to the higher spectral resolution and sensitivity with respect to the $\mathrm{C}=\mathrm{C}, \mathrm{C}-\mathrm{C}, \mathrm{C}-\mathrm{O}$, and $\mathrm{C}-\mathrm{N}$ bonds. Thus, the latter can better assess microstructural changes (polymerization, de-polimerisation) and formation of new compounds containing conjugated $\mathrm{C}=\mathrm{C}$ bonds.

Effects of ageing were assessed through the comparison of Raman bands (frequency shifts, intensity and shape changes) of the fresh and aged samples of proteins binders [14,15], lipids [16,17], and natural resins $[18,19]$. Recently, micro-Raman spectroscopy has been also 
Table 1

Resins, solvents and illuminance used for the experiment.

\begin{tabular}{|c|c|c|c|c|c|}
\hline Resins & Group & No. of carbon atoms & Solvent & Illuminance at sample surface (lx) & Total illuminance (Mlx in 45 days) \\
\hline Dammar & Triterpenoid & 30 & Ligroin & 19,000 & 14.0 \\
\hline Mastic & Triterpenoid & 30 & Ethanol & 17,750 & 12.5 \\
\hline Colophony & Diterpenoid & 20 & Ethanol & 11,200 & 9.0 \\
\hline Sandarac & Diterpenoid & 20 & Ethanol & 19,500 & 14.0 \\
\hline Shellac & Sesquiterpenoid & 15 & Ethanol & 19,400 & 14.0 \\
\hline
\end{tabular}

used for assessing the chemical changes induced by UV laser radiation on naturally cured and artificially aged varnishes [20].

In this work, for the first time, Raman spectroscopy has been employed for continuously monitoring the complex molecular dynamics of natural resins, which occur during their ageing under artificial light exposure. In particular, a portable, temperature-controlled, Raman device (excitation wavelength $1064 \mathrm{~nm}$ ) has been developed in order to automatically monitor the ageing process by preventing phase changes and other undesired alteration effects. Temperature control of the sample's irradiated surface was achieved by means of a pyroelectric sensor and dedicated software producing a feedback on the laser power supply and then a suitable modulation of the output beam. It allows collecting a sequence of spectra in the same area of analysis by setting fixed maximum temperature and total radiant exposure.

One spectrum every $4 \mathrm{~h}$ has been measured during the whole ageing period of 45-days. Samples were prepared by applying various terpenoid resins (colophony, shellac, dammar, sandarac, mastic) on Polyethylene (PE) thin film and subjected to artificial ageing in order to simulate natural light exposure in indoor museum conditions. Total irradiance of 9-14 Mlx was used which can be compared, assuming reciprocity, to about 16-28 years of exposure in recommended museum conditions (150-200 lx 8 h/day). Natural resins have been intensively used in the past and they are still employed as adhesives, binders and varnishes.

Intensity changes of the bands in Raman spectra have indicated structural modifications after the ageing process which allowed describing the chemical alteration dynamics of molecular bonds over time.

\section{Materials and methods}

Homogeneous saturated solutions of fresh grinded natural terpenoid resins (constituted of units of $\mathrm{C}_{5}$ compound isoprene) were prepared, dissolving the material in the appropriate solvent and stirred for 1 day. All the formulations were dropped on very thin polyethylene (PE) slides. Ethanol and ligroin were used as solvents for dissolving the resins according to Table 1 . Resins employed for the experiment are dammar, mastic, colophony, sandarac and shellac. Dammar is a triterpenoid resin largely composed of tetracyclic dammarane series $\left(\mathrm{C}_{30} \mathrm{H}_{54}\right)$, the pentacyclic compound ursonic acid $\left(\mathrm{C}_{30} \mathrm{H}_{46} \mathrm{O}_{3}\right)$ and a proportion of polymeric hydrocarbon. Mastic is a triterpenoid resin composed of several tetracyclic compounds of the euphane series, including masticadienonic acid $\left(\mathrm{C}_{30} \mathrm{H}_{46} \mathrm{O}_{3}\right)$. Colophony and Sandarac are diterpenoid resins composed mainly of abietic acid $\left(\mathrm{C}_{20} \mathrm{H}_{30} \mathrm{O}_{2}\right)$ and sandaracopimaric acid $\left(\mathrm{C}_{20} \mathrm{H}_{30} \mathrm{O}_{2}\right)$ respectively. Shellac is a sesquiterpenoid extracted from insects with very complex composition: probable primary components are jalaric $\left(\mathrm{C}_{15} \mathrm{H}_{22} \mathrm{O}_{5}\right)$ and laccijalaric acid $\left(\mathrm{C}_{15} \mathrm{H}_{20} \mathrm{O}_{4}\right)[21]$.

A portable Raman device was conveniently assembled in the lab by using a narrow-band CW diode-pumped Nd:YAG(1064 nm) laser and a NIR-spectrometer equipped with an InGaAs linear array. A specific probe was designed in order to control the local temperature rise of the area under analysis. To this goal a pyroelectric sensor was used, which provides the feedback for suitably modulating the output power of the laser source and then limiting undesired heating effects within the gauge volume. Furthermore, a dedicated rotating wheel moved by a USB servo motor was designed as sample holder (Fig. 1).
Resins solutions were dropped into special pits over the wheel surface. The rotation allowed samples sliding between the positions designated for the acquisition of the Raman spectra and that for artificial ageing. All the experimental parameters including the time of exposure to light and spectra acquisition were set in the control code and a completely automated measurement cycles was launched.

Light ageing was carried out under six 55 Watt OSRAM DULUX® (range 380-780 nm) daylight fluorescent tubes (5400 K color temperature). As the ultraviolet content of the light emitted by these lamps is relatively low no further ultraviolet filter was used.

The light flow in lux, or illuminance, was measured at the surface of each sample through a lux meter in order to consider irradiation slight inhomogeneity. The illuminance ( $\mathrm{lx}$ ) and light dose $(\mathrm{MlX} * \mathrm{~h})$ delivered to each sample during 45-days of irradiation are reported in Table 1.

During the early 5-days of measuring, Raman spectra were acquired after every $1 / 2 \mathrm{~h}$ irradiation in order to follow the initial fastest molecular changes in more detail, as, for example, those associate with the solvent evaporation.

During the following 40-days Raman spectra were collected every $4 \mathrm{~h}$ for a total irradiance of 9-14 Mlx which can be compared, assuming reciprocity, to about $16-28$ years of exposure in recommended museum conditions (150-200 lx 8 h/day). Acquisition time for Raman spectra of $4 \mathrm{~min}$ and laser output power of about $300 \mathrm{~mW}$ were employed during the experiment. In these conditions a maximum temperature of $35^{\circ} \mathrm{C}$ was reached during laser irradiation, which is lower than those of the glass transition of the various resins [22].

Peak deconvolution was carried out using Origin Pro 2015 in order to investigate molecular changes induced by light ageing over time. The local maximum method with high sensibility was used as peak finding settings and the Lorentzian peak function was preferred to Gaussian and Gaussian-Lorentzian profiles since it provided the highest Rsquare value.

The need of an automated measurement protocol has been justified by the following reasons. First, Raman measurements of this work need very high spatial accuracy because the samples cannot be considered

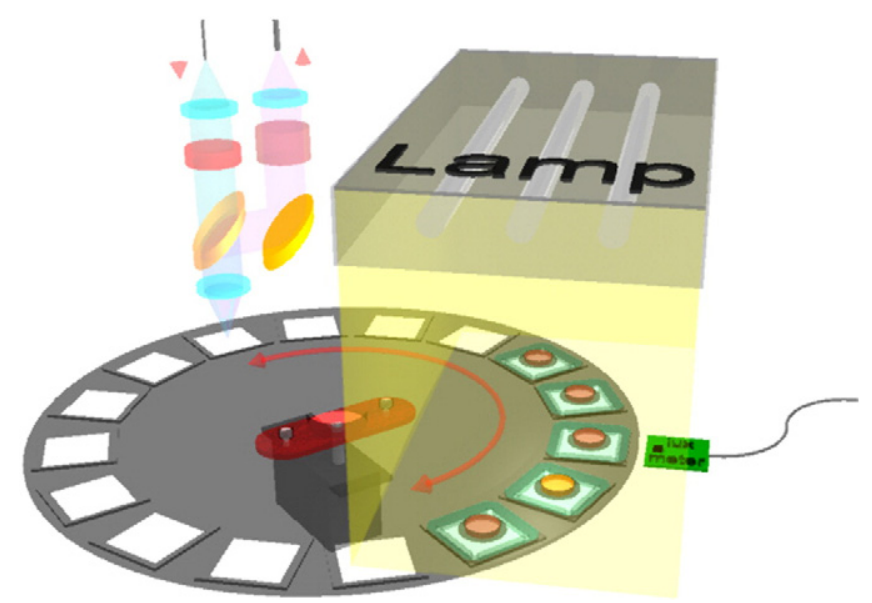

Fig. 1. Automated Raman setup used for characterizing resins degradation. 

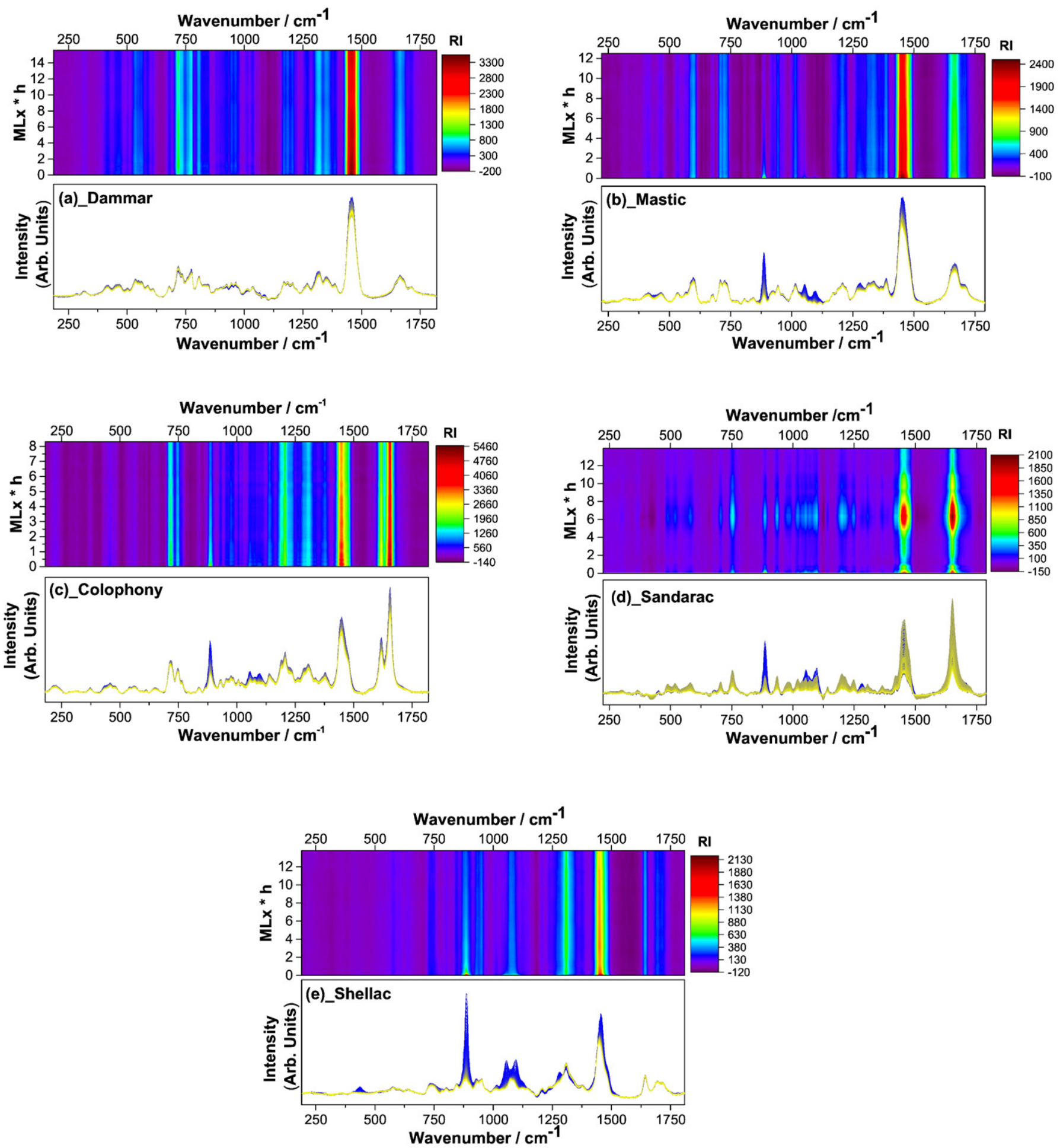

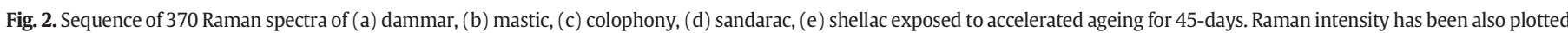
as function of total irradiance in a 2D-map for easy viewing.

homogeneous systems and, thus, the time dependent spectra must be collected exactly in the same position. Second, the experiment is rather time consuming taking into account that the total time needed for acquiring the spectra is about 21 working days. Finally, in case of manual measurements the time distribution of the measurements would have been non-homogeneous.

\section{Results}

Fig. 2 shows the sequence of the 370 Raman spectra acquired during 45-days exposure for each resin sample. Spectra are ordered by irradiance using a color palette from blue hues for low irradiance values to red hues for the high values. After acquisition, the spectra were 
subjected to a background subtraction through polynomial fitting for comparison purposes. In some details, a number of baseline points were selected for the spectral set of a given resin in order to fit and subtract the background of each spectrum using a polynomial of a suitable order (from 3 to 9 ).

Examining the sequence of spectra along with the plot of the bands intensity vs the irradiance in a 2D-map, the perception of the molecular dynamics due to the irradiation process becomes immediate and clear.

For instance, in all the resins dissolved in ethanol such as colophony, mastic, sandarac and shellac, the evaporation process of the solvent is clearly identifiable in every spectrum. In particular, the intensity of the main ethanol Raman bands at 1096, 1057 and $885 \mathrm{~cm}^{-1}$, which correspond to $\delta\left(\mathrm{CH}_{3}\right), v_{\mathrm{a}}(\mathrm{CCO})$ and $v_{\mathrm{s}}(\mathrm{CCO})$ vibrational modes, respectively, undergo a rapid decrease as the irradiance increases. Moreover, in the case of sandarac and shellac resins a decrease of the minor ethanol Raman bands at 1278 and $436 \mathrm{~cm}^{-1}$ is observable as well. With regard to the molecular dynamic of the band at $1457 \mathrm{~cm}^{-1}$ corresponding to the $\delta(\mathrm{COH})$ mode of ethanol, a curve-fitting process is necessary in order to separate the contribution of the $v\left(\mathrm{CH}_{2}\right) / \delta\left(\mathrm{CH}_{2}\right)$ modes of the resin itself. The intensity trend of ethanol bands of shellac as a function of irradiance is shown in Fig. 3 as an example. It is noteworthy that the intensity of the Raman band of ethanol at $1457 \mathrm{~cm}^{-1}$ remains high even at higher irradiance values because it is overlapped with the intense $v\left(\mathrm{CH}_{2}\right)$ mode of the resin which, as previously mentioned, has similar vibrational frequency. Besides this, the amount of solvent retained in the bulk of varnish undergoes a relatively fast exponential decay. Specifically, an intensity decreasing of $37 \%$ is seen after $0.1 \mathrm{MLX} *$ h of exposure and only after $2 \mathrm{MlX} * \mathrm{~h}$, the intensity of peaks related to solvent drops down to about $7 \%$.

Besides molecular changes due to the intrinsic alteration processes of the resins, variations in Raman bands intensity can sometimes be due to external factors as well. This was the case of sandarac resin, where a temporary increase of the intensity was observed for every band in the spectra for irradiance values between 4 and 9 MLx (Fig. 2 ). This behavior can be ascribable to the formation of bubbles inside the volume of resin during the drying process the movement of which towards the surface can lead to some variations in the Raman scattering efficiency. Sandarac resin was indeed the only sample showing the presence of bubbles in the surface after irradiation.

Molecular dynamics of resins are definitely slower than those correlated to the evaporation of solvents. Although the completion of the

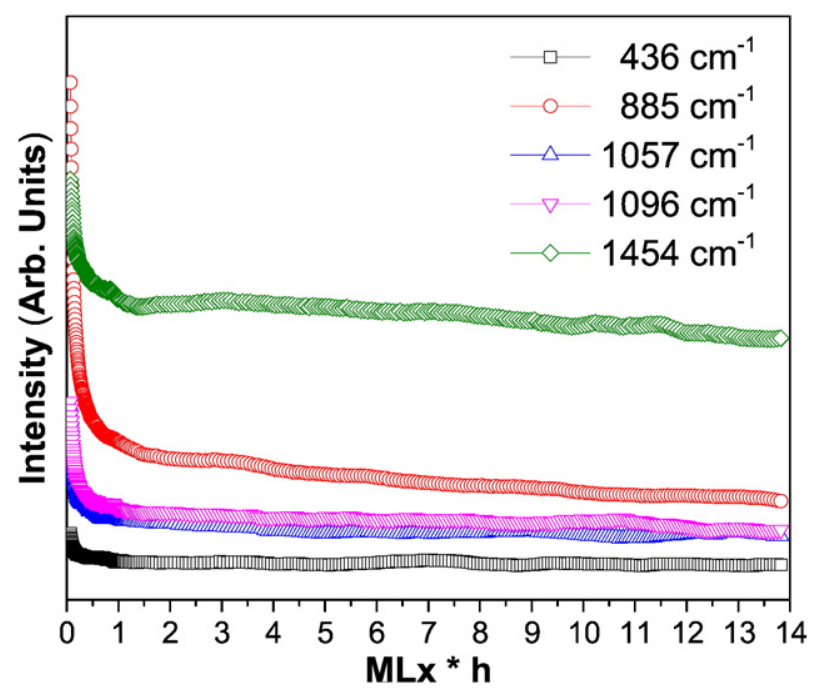

Fig. 3. Intensity trend of ethanol bands of shellac as a function of irradiance. complex reaction mechanisms due to resins degradation might require very long time, the accelerated ageing simulating 26-years of exposure to lighting performed in this work has nevertheless led to tracking the early molecular changes taking place during the polymerization and the degradation of terpenoid varnishes.

In this respect, the latter were accurately monitored in the 1550$1800 \mathrm{~cm}^{-1}$ region, where neither ligroin nor ethanol show significant bands. The results achieved after the curve-fitting process using the Lorentzian shape are displayed in Fig. 4.

Raman spectrum of dammar varnish was well fitted with four peaks with maximum centered at about 1648, 1664, 1679 and $1712 \mathrm{~cm}^{-1}$. These bands and the related shoulders are assigned to stretching vibrations of $\mathrm{C}=\mathrm{C}$ and $\mathrm{C}=\mathrm{O}$ bonds, which are typically found in oleanane and ursonic molecules. Similarly, mastic, although is a triterpenoid resin, may be distinguished by dammar due to the lack of the shoulders at 1648 and $1679 \mathrm{~cm}^{-1}$. As regards diterpenoid resin, colophony is characterized by two representative signals ascribable to $\mathrm{C}=\mathrm{C}$ stretch of abietadiene compounds. The most dominant bands at $1654 \mathrm{~cm}^{-1}$ is assigned to trans conjugated $\mathrm{C}=\mathrm{C}$ of abietic acids and the less intense at $1617 \mathrm{~cm}^{-1}$ to the symmetric stretching of $\mathrm{C}=\mathrm{C}$ in the aromatic ring $[23,24]$. The latter may be related to the presence of dehydroabietic acids, which is known to be formed upon oxidation over time [25]. Contrarily to abietane-type resins, the intense narrow band centered at $1651 \mathrm{~cm}^{-1}$ in sandarac sample may be instead assigned to $C=C$ stretch of vinyl group present in the side chain of communic acid, which is very reactive and readily undergoes polymerization reaction [26,27]. In contrast to colophony, a very weak contribution at about $1700 \mathrm{~cm}^{-1}$ may be also noticed.

With regard to shellac, the contribution of the band at $1643 \mathrm{~cm}^{-1}$ is ascribed to $\mathrm{C}=\mathrm{C}$ stretching deriving from the main resinous acids (i.e. shellolic and jalaric acids) while the other two bands, at 1691 and $1717 \mathrm{~cm}^{-1}$ are due to the $\mathrm{C}=\mathrm{O}$ in carboxylic acids.

Taking into account the fact that among the bands described above those corresponding to the stretching of $\mathrm{C}=\mathrm{C}$ are characterized by a higher Raman cross section than $\mathrm{C}=\mathrm{O}$ ones, they were chosen as useful markers for the monitoring of the polymerization and degradation processes of the present natural resins. To this aim, the results obtained from Lorentzian peak fitting of the main $\mathrm{C}=\mathrm{C}$ vibrational modes are shown in Fig. 5 as function of total radiation dose. First of all, it is worth noting as the center max and FWHM do not vary significantly upon the irradiation time, although a slight broadening starting after 4 Mlx of exposure is observed for dammar varnish. Besides this, the most relevant modifications are due to the minute decrease of the area and intensity of the $\mathrm{C}=\mathrm{C}$ bonds, which can be mainly ascribed to oxidation and cross-linking. Surprisingly, $\mathrm{C}=\mathrm{C}$ bonds in dammar and even more in mastic result quantitatively decreased, most likely as consequence of the cleavage of unsaturated ketones via Norrish type reactions leading to oxidized functional groups $[7,19]$.

In contrast to the triterpenoid resins, $\mathrm{C}=\mathrm{C}$ bonds in colophony and sandarac undergo a significant reduction either in the peak-area and maximum height. As regards colophony, a similar decrease was seen also in the band at $1617 \mathrm{~cm}^{-1}$ (data not shown). On the other hand, diterpenoid resins, being rich of conjugated carbon-carbon double bonds within and outside the terpenoid ring, are readily prone to isomerization and polymerization.

As expected, the signal of $\mathrm{C}=\mathrm{C}$ bond in shellac resin, deriving mainly from shellolic and jalaric acids, is only weakly affected by ageing, although after longer time of exposure under intense light fluxes tends to be reduced.

\section{Conclusions}

In this work, Raman spectroscopy has been employed for the first time in order to continually monitor molecular dynamics of natural resins exposed to accelerated ageing. The exposure to artificial light for 45-days has led to significant changes especially concerning the 
intensity of the Raman bands allowing the characterization of the alteration process. In particular, the automated acquisition of a large number of spectra overtime during light-exposure has given the possibility to distinguish fast dynamics, mainly associated to solvent evaporation, from those slower due to resins photo-oxidation processes. Furthermore, the use of a rotating wheel, which has ensured that each spectrum of every sample was acquired in exactly the same spot, along with the use of a macro approach ( $1 \mathrm{~mm}$ laser beam diameter), has made the comparison of spectra more trustworthy avoiding problems due to material inhomogeneities as well as to the nonuniformity of the ageing process. Also the use of a pyroelectric sensor for modulating the output power of the laser source has been crucial in order to
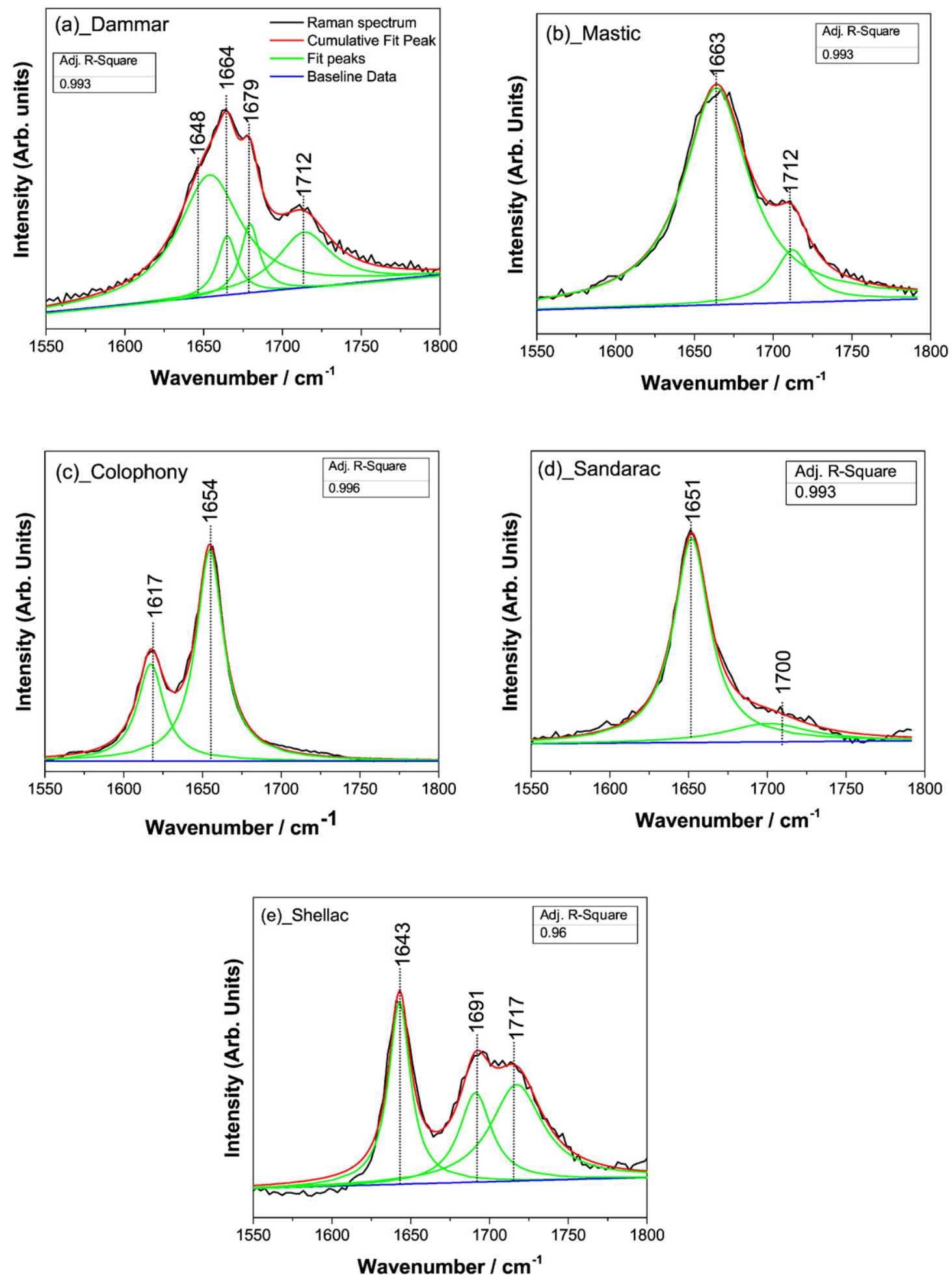

Fig. 4. Peak deconvolution of $\mathrm{C}=\mathrm{C}$ and $\mathrm{C}=\mathrm{O}$ stretching modes for the different resin studied. Raman spectra reported refer to samples prior to be exposed to artificial ageing. 

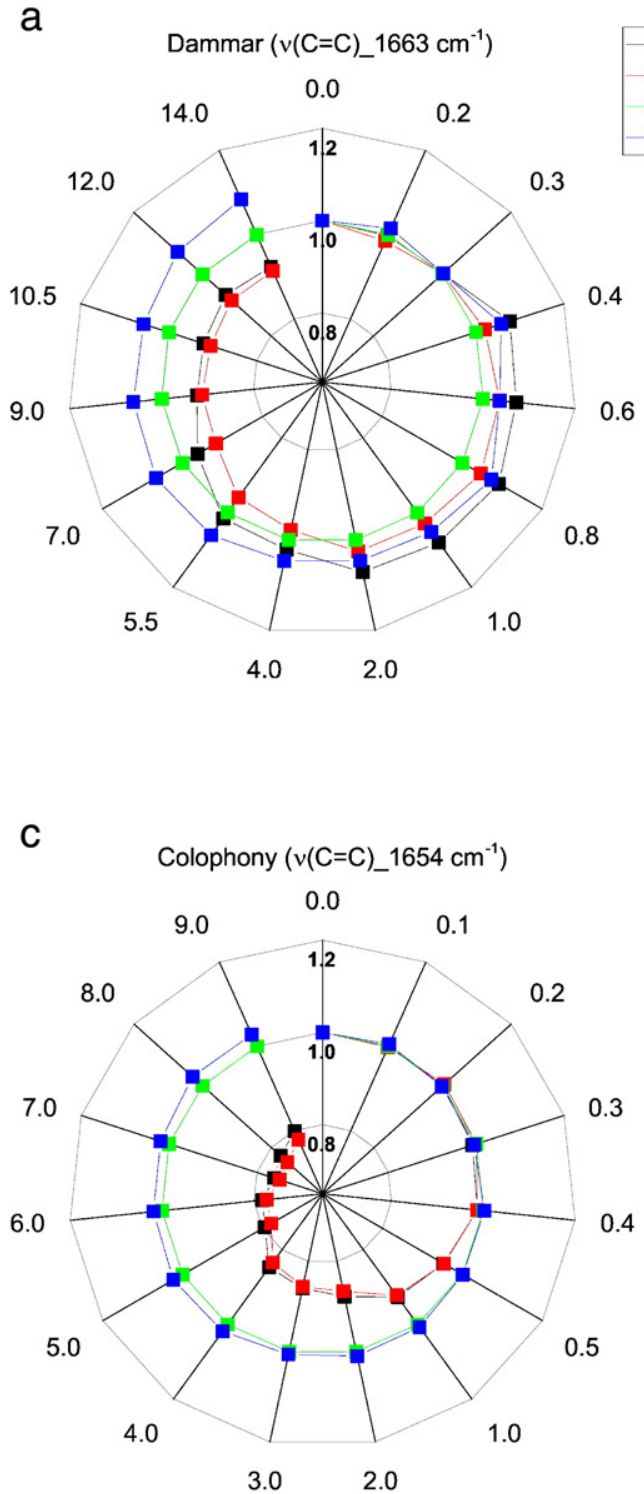
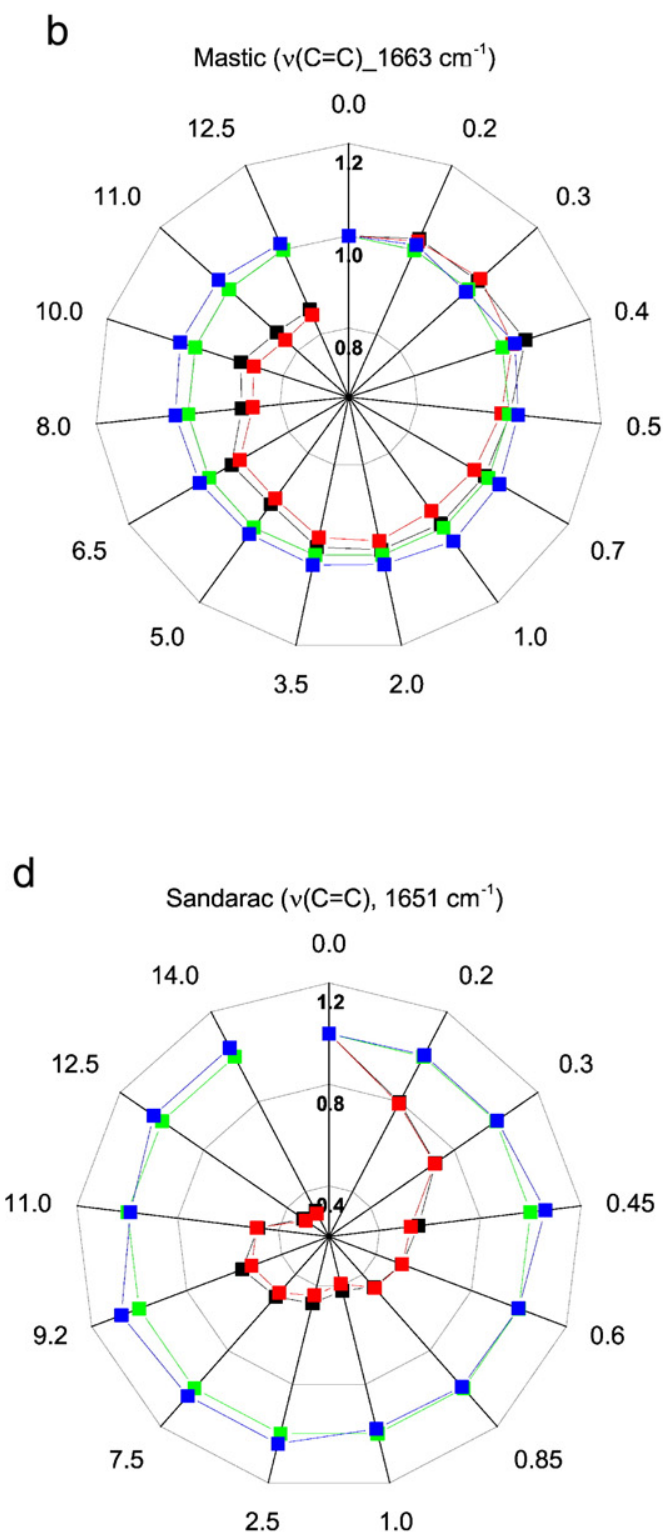

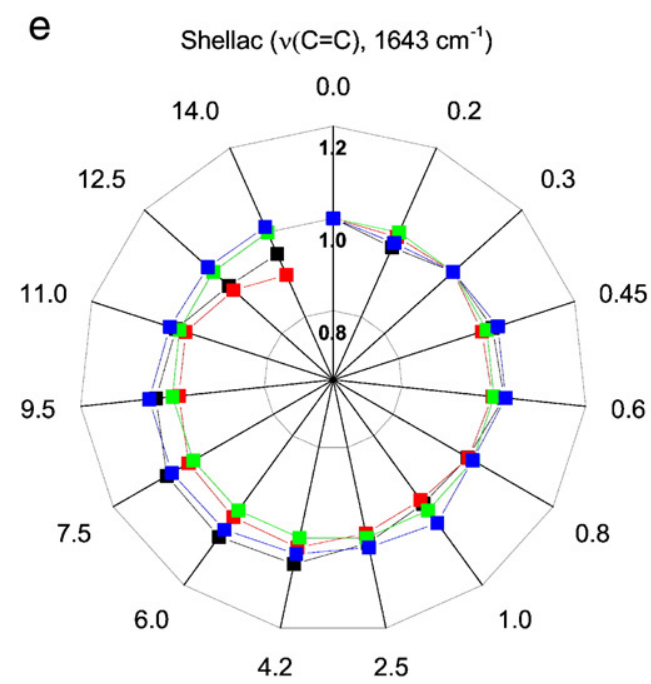

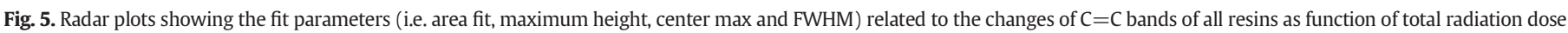
delivered. 
avoid undesired heating effects due to laser irradiation such as glass transitions. We are really confident that this kind of approach can be effectively capable not only to continuously assess molecular changes due to the degradation of the polymers themselves but also to understand how their interaction with other materials (i.e. heavy-metals ions, pigments and other binders) may affect the time of ageing and the formation of specific final altered compounds.

\section{Acknowledgements}

The present study was carried out in the framework of the European Project IPERION CH - Integrated Platform for the European Research Infrastructure on Cultural Heritage (H2020-INFRAIA-2014-2015, Grant Agreement n. 654028).

\section{References}

[1] L. Brambilla, C. Riedo, C. Baraldi, A. Nevin, M.C. Gamberini, C. D'Andrea, O. Chiantore, S. Goidanich, L. Toniolo, Characterization of fresh and aged natural ingredients used in historical ointments by molecular spectroscopic techniques: IR, Raman and fluorescence, Anal. Bioanal. Chem. (2011) 1827-1837, http://dx.doi.org/10.1007/ s00216-011-5168-z

[2] G. Pastorelli, C. Cucci, O. Garcia, G. Piantanida, A. Elnaggar, M. Cassar, M. Strlic, Environmentally induced colour change during natural degradation of selected polymers, Polym. Degrad. Stab. 107 (2013) 198-209, http://dx.doi.org/10.1016/j. polymdegradstab.2013.11.007.

[3] M. Strlič, I.K. Cigić, I. Rabin, J. Kolar, B. Pihlar, M. Cassar, Autoxidation of lipids in parchment, Polym. Degrad. Stab. 94 (2009) 886-890, http://dx.doi.org/10.1016/j. polymdegradstab.2009.03.003.

[4] V. Pintus, M. Schreiner, Characterization and identification of acrylic binding media: influence of UV light on the ageing process, Anal. Bioanal. Chem. 2961-2976 (2011), http://dx.doi.org/10.1007/s00216-010-4357-5.

[5] E. Ghelardi, I. Degano, M.P. Colombini, J. Mazurek, M. Schilling, H. Khanjian, T. Learner, A multi-analytical study on the photochemical degradation of synthetic organic pigments, Dyes Pigments 123 (2015) 396-403, http://dx.doi.org/10.1016/j. dyepig.2015.07.029.

[6] M.T. Doménech-carbó, M.F. Silva, E. Aura-castro, L. Fuster-lópez, S. Kröner, M.L. Martínez-bazán, X. Más-Barberá, M.F. Mecklenburg, L. Osete-Cortina, A. Doménech, J.V. Gimeno-Adelantado, D.J. Yusá-Marco, Study of behaviour on simulated daylight ageing of artists' acrylic and poly (vinyl acetate) paint films, Anal. Bioanal. Chem. 2921-2937 (2011), http://dx.doi.org/10.1007/s00216-010-4294-3.

[7] D. Ciofini, J. Striova, M. Camaiti, S. Siano, Photo-oxidative kinetics of solvent and oilbased terpenoid varnishes, Polym. Degrad. Stab. 123 (2016) 47-61, http://dx.doi. org/10.1016/j.polymdegradstab.2015.11.002.

[8] T. Poli, A. Piccirillo, A. Zoccali, C. Conti, M. Nervo, O. Chiantore, The role of zinc white pigment on the degradation of shellac resin in artworks, Polym. Degrad. Stab. 102 (2014) 138-144, http://dx.doi.org/10.1016/j.polymdegradstab.2014.01.026.

[9] L. Ghezzi, C. Duce, L. Bernazzani, E. Bramanti, M.P. Colombini, M.R. Tiné, I. Bonaduce, Interactions between inorganic pigments and rabbit skin glue in reference paint reconstructions, J. Therm. Anal. Calorim. 122 (2015) 315-322, http://dx.doi.org/10. 1007/s10973-015-4759-X.

[10] A. Pallipurath, J. Skelton, S. Bucklow, S. Elliott, A chemometric study of ageing in lead-based paints, Talanta 144 (2015) 977-985, http://dx.doi.org/10.1016/j. talanta.2015.07.037.
[11] V. Otero, D. Sanches, C. Montagner, M. Vilarigues, L. Carlyle, J. A. Lopes, M. J. Melo, Characterisation of metal carboxylates by Raman and infrared spectroscopy in works of art, J. Raman Spectrosc. 45 (2014) 1197-1206. http://dx.doi.org/10.1002/ jrs.4520.

[12] D.L.A. De Faria, H.G.M. Edwards, M.C. Afonso, R.H. Brody, J.L. Morais, Raman spectroscopic analysis of a tembetá: a resin archaeological artefact in need of conservation, Spectrochim. Acta 60 (2004) 1505-1513, http://dx.doi.org/10.1016/j.saa.2003.08. 025.

[13] P. Vandenabeele, B. Wehling, L. Moens, H. Edwards, M. De Reu, G. Van Hooydonk, Analysis with micro-Raman spectroscopy of natural organic binding media and varnishes used in art, Anal. Chim. Acta 407 (1) (2000) 261-274.

[14] A. Nevin, I. Osticioli, D. Anglos, A. Burnstock, S. Cather, E. Castellucci, The analysis of naturally and artificially aged protein-based paint media using Raman spectroscopy combined with Principal Component Analysis, J. Raman Spectrosc. 39 (2008) 993-1000, http://dx.doi.org/10.1002/jrs.

[15] I. Osticioli, A. Nevin, D. Anglos, A. Burnstock, S. Cather, M. Becucci, et al., MicroRaman and fluorescence spectroscopy for the assessment of the effects of the exposure to light on films of egg white and egg yolk, J. Raman Spectrosc. 39 (2008) 307-313, http://dx.doi.org/10.1002/jrs.

[16] E. Manzano, J. García-Atero, A. Dominguez-Vidal, M.J. Ayora-Cañada, L.F. CapitánVallvey, N. Navas, Discrimination of aged mixtures of lipidic paint binders by Raman spectroscopy and chemometrics, J. Raman Spectrosc. (2011), http://dx.doi. org/10.1002/jrs.3082 n/a-n/a.

[17] A. Schönemann, H.G.M. Edwards, Raman and FTIR microspectroscopic study of the alteration of Chinese tung oil and related drying oils during ageing, Anal. Bioanal. Chem. 400 (2011) 1173-1180, http://dx.doi.org/10.1007/s00216-011-4855-0.

[18] C. Daher, L. Bellot-Gurlet, Non-destructive characterization of archaeological resins: seeking alteration criteria through vibrational signatures, Anal. Methods 5 (2013) 6583, http://dx.doi.org/10.1039/c3ay41278d.

[19] A. Nevin, D. Comelli, I. Osticioli, L. Toniolo, G. Valentini, R. Cubeddu, Assessment of the ageing of triterpenoid paint varnishes using fluorescence, Raman and FTIR spectroscopy, Anal. Bioanal. Chem. 395 (2009) 2139-2149, http://dx.doi.org/10.1007/ s00216-009-3005-4.

[20] D. Ciofini, M. Oujja, S. Cañamares, M.Castillejo Siano, Spectroscopic assessment of the UV laser removal of varnishes from painted surfaces, Microchem. J. 124 (2016) 792-803, http://dx.doi.org/10.1016/j.microc.2015.10.031.

[21] J.S. Mills, R. White, The Organic Chemistry of Museum Objects, second ed. Butterworth Heinemann, 1999.

[22] M.R. Schilling, The glass transition of materials used In conservation, Stud. In Conserv. 34 (3) (1989) 110-116.

[23] R.H. Brody, H.G. Edwards, A.M. Pollard, Fourier transform-Raman spectroscopic study of natural resins of archaeological interest, Biopolymers 67 (2) (2002) 129-141, http://dx.doi.org/10.1002/bip.10059.

[24] M. Nuopponen, S. Willför, A.S. Jääskeläinen, A. Sundberg, T. Vuorinen, A UV resonance Raman (UVRR) spectroscopic study on the extractable compounds of scots pine (Pinus sylvestris) wood: part I: lipophilic compounds, Spectrochim. Acta A 60 (2004) 2953-2961, http://dx.doi.org/10.1016/j.saa.2004.02.008.

[25] A. Findeisen, V. Kolivoska, I. Kaml, W. Baatz, E. Kenndler, Analysis of diterpenoic com-pounds in natural resins applied as binders in museum objects by capillary electrophoresis, J Chroma-togr. A. 1157 (2007) 454-461, http://dx.doi.org/10. 1016/j.chroma.2007.05.010.

[26] H.G.M. Edwards, D.W. Farwell, L. Daffner, Fourier-transform Raman spectroscopic study of natural waxes and resins. I, Spectrochim. Acta A 52 (1996) 1639-1648.

[27] D. Lau, M. Livett, S. Prawer, Application of surface-enhanced Raman spectroscopy (SERS) to the analysis of natural resins in artworks, 39 (2008) 545-552, http:// dx.doi.org/10.1002/jrs. 